\title{
Cross-cultural issues in linguistic, visual-quantitative, and written-numeric supports for mathematical thinking
}

\author{
Karen C. Fuson · Yeping Li
}

Accepted: 23 April 2009/Published online: 19 May 2009

(C) The Author(s) 2009. This article is published with open access at Springerlink.com

\begin{abstract}
An in-depth analysis of the major early numerical aspects (single-digit and multidigit addition and subtraction) in a representative Chinese textbook series and a US textbook series (Math Expressions) with major East Asian components illustrated how linguistic issues create different teaching and learning tasks for the same mathematical topic and how additional meaning-making supports may be needed in the US. Analyses of multidigit methods in several East Asian textbooks revealed a wide range of written-numeric support of the steps in these operations. Coherence and learning paths in both programs were identified. A framework that identifies elements of a coherent learning path of meaning-making supports is proposed to facilitate future cross-cultural analyses.
\end{abstract}

Keywords Addition - Subtraction - Language effects · Learning supports - Cross-cultural textbook analysis

\section{Introduction}

East Asian students outperform US students on several measures of performance. This special issue is focused on curricular analyses that can increase our understanding of this phenomenon and also increase our understanding of social-cultural practices that help develop teacher and student understanding of mathematics in China (and other

K. C. Fuson $(\square)$

Northwestern University, Evanston, IL, USA

e-mail: karenfuson@mac.com

Y. Li

Texas A\&M University, College Station, TX, USA

e-mail: yepingli@tamu.edu
East Asian countries) and in the United States. Analyses of the mathematics topic content of the intended, implemented, and achieved curriculum are vital as a basis for understanding national differences (e.g., Cai, 2008; Li, 2007a). But there are also language differences and differences in textbook support that affect the clarity of the mathematical concepts and procedures to be taught and learned, both for teachers and for students. These classes of differences are the focus of the present paper.

This article is a collaboration between a western researcher who has been studying East Asian mathematics education approaches for over 20 years in collaboration with graduate students from Korea, Taiwan, and Japan and a researcher from China who has been living in the United States for over 15 years and studying mathematics curriculum issues between the East and the West. Two textbook series are the primary foci of the analysis, but the analysis is also informed by the authors' familiarity with other East Asian and US textbooks over the years. The Chinese books are those recently published by People's Education Press which is under the direct administration of the Ministry of Education in the Chinese Mainland (Division of Elementary Mathematics, 2007). This textbook series is currently the most widely used series with over $60 \%$ of the market in China. The US books are those from the Children's Math Worlds Research Project that are now published by Houghton Mifflin Harcourt as Math Expressions (Fuson, 2006, 2009a). This textbook program is used widely in the US (in 49 of the 50 states), but has a relatively small market share at this time. This textbook program was developed in an extended research project carried out over 12 years to adapt some approaches from East Asia for US use but also to develop new approaches to meet special US needs. The recent Chinese books differ from older Chinese books or from the Korean, Taiwanese, and Japanese books 
examined by the authors in earlier years in important ways. Such differences will be mentioned during the analysis, but extensive comparative analyses are beyond the scope of this article.

This curricular analysis article focuses on the first four major computational topics that students experience: single-digit addition, single-digit subtraction, multidigit addition, and multidigit subtraction. The selection of these four topics provides an opportunity to understand possible linguistic influence on students' early learning of school mathematics and to ascertain the coherence of this early numerical experience. This article results from an in-depth examination of the textbook supports that enable early mathematical ideas to be built in powerful and connected ways. Our analysis reveals the kinds of supports that can extend readily from East Asia to the United States but also identifies some limits of such extensions and necessary adaptations (Li, 2007b). Because the Math Expression program is unusual for the United States in the coherence and clarity of its learning supports, ways in which it departs from usual US texts will be identified along the way. The program's deep re-working of learning supports from East Asia also suggests some ideas that might be helpful in China and other East Asian countries. The authors see this article as potentially useful for teachers and teacher educators as well as for researchers because seeing ideas in somewhat different contexts always enriches and extends one's own thinking.

\section{A coherent learning path of meaning-making supports?}

Language plays a key role in mathematics learning and teaching (e.g., Chen \& Li, 2008). It is used to express mathematical ideas and to discuss and explain these ideas and related solution methods. Languages vary in how clearly they express mathematical ideas, with East Asian languages often expressing ideas more clearly than does English (specific issues are discussed later in the paper). The clarity of East Asian languages vis a vis numerical concepts can help speed initial learning of a concept and increase the understanding that occurs in classroom discourse using these clearer words. An examination of language use in textbooks should thus allow us to understand possible linguistic supports that may facilitate students' mathematics learning, especially when viewed through a cross-cultural lens that permits us to see how those terms are expressed in another language. In particular, we are interested in understanding whether the Chinese language as used in school textbooks lends different supports to mathematical methods in comparison to English.
Illustrations of various kinds are widely used in texts, and relevant research has revealed the potential of illustrations in facilitating students' learning (e.g., Levie \& Lentz, 1982). However, not all illustrations in texts facilitate students' learning (Garner, Brown, Sanders, \& Menke, 1992; Woodward, 1987). Mayer, Sims, \& Tajika (1995) documented the inclusion of many instructionally irrelevant illustrations in US texts but only the inclusion of illustrations that clarified the mathematical idea in Japanese texts. The study of Mayer et al., demonstrated the feasibility and value of examining text illustrations for revealing potential impact of texts on students' mathematical understanding. We therefore include this focus on the nature and instructional function of text illustrations in the US and Chinese texts. We call such clarifying text illustrations visual-quantitative supports because they show visually important quantitative aspects of the concepts involved. These visual-quantitative supports may show a real-world situation like nine blue pens and six red pens, or simple mathematical drawings like a rectangle with two rows of five circles in it, or pictures or drawings of pedagogical teaching tools like bundles of ten sticks and single sticks to show two-digit numbers.

Another variation we found in the textbooks we examined is the extent to which the written numerical method supported understanding and notated intermediate steps in the method. These written-numeric supports make the written method more accessible to students and easier to carry out. Our analysis will summarize the range of these written-numeric supports.

The methodology for this paper was a detailed content analysis that identified visual-quantitative learning supports and written-numeric aspects of addition and subtraction methods given in the Chinese and US books. Every page was examined and notes were taken. These were summarized and then numeric methods for multidigit addition and subtraction from Japanese, Korean, and other Chinese books were added to the analysis. The linguistic analysis began with the issues already known by the authors (e.g., differences in the clarity of the tens and ones in Chinese and English number words) and were extended by translating into English the Chinese words on key textbook pages (those introducing or extending methods).

Previous analyses of East Asian textbooks have emphasized their coherence in content development and the power of their meaning-making supports $(\mathrm{Li}, 2008$; Murata, 2004, 2008; Murata \& Fuson, 2001, 2006; Watanabe, 2006). Fuson and Murata (2007) extended these points by describing teaching principles drawn from US National Research Council reports, the NCTM process standards, and from teaching in Japanese classrooms. In addition to the importance of the above features of language and textbook illustrations as meaning-making 
supports, they identify the importance of a coherent learning path that supports student movement from primitive to more advanced methods that are mathematically desirable. Mathematically-desirable methods show important mathematical features, generalize across numbers and situations, and are efficient enough. Fuson and Murata also discuss how it is possible to teach mathematically-desirable methods but also make them accessible to students so that students can understand them. Therefore our analysis in this paper will also focus on the extent to which the whole range of student methods from primitive to advanced are shown in the book because this helps the teacher recognize these methods but also move students along the learning path to general mathematically-desirable methods. These focal research issues are summarized in Table 1 as a framework that future crosscultural analyses of textbooks can use and modify. This framework is a result of the study and was clarified as we worked on the analysis. Table 1 may better be placed at the end rather than at the beginning of the paper, but its placement here allows it to act as an advance organizer for the issues to be addressed and has enabled us to introduce and explain here the terminology that will be used later in the paper.

\section{The four computational mathematics topics: single-digit addition, single-digit subtraction, multidigit addition, and multidigit subtraction}

\subsection{Single-digit addition and subtraction methods}

First, language differences that make certain methods more difficult in English than in East Asian languages based on Chinese are described. Second, levels of experience/embeddedness in single-digit methods are outlined. Third, the visual-quantitative learning supports in Chinese books are discussed. Finally, how and why the learning supports in the US program vary from those in the Chinese books is explained.

\subsubsection{Language differences and single-digit strategies}

The English teen number words (eleven, twelve, thirteen, fourteen, fifteen, sixteen, seventeen, eighteen, nineteen) do not show their quantitative meanings of $11,12,13, \ldots, 19$ as one ten and some ones $(11=10+1,12=10+2$, etc). In contrast, the regular Chinese words clearly name the tens in these teen words; these words in their English translation are ten one, ten two, ten three, ..., ten nine. In

Table 1 A framework for cross-cultural analysis: are there visual-quantitative, written-numeric, and any necessary linguistic meaning-making supports that culminate in a coherent learning path leading to a mathematically-desirable and accessible method(s)?

Coherent learning path of meaning-making supports

The teacher or math program creates a cognitively-supportive meaning-focused classroom by using a coherent learning path of linguistic, visual-quantitative, and written-numeric supports to create interest and accessibility of ideas and support students in learning methods that are mathematically desirable but also accessible (adapted from Fuson \& Murata, 2007)

Research questions for the textbook analyses

Part 1.

Does the textbook contain visual-quantitative meaning-making supports that clarify the mathematical concepts?

What are the visual supports and how well do they support the mathematical ideas?

Could students make math drawings to link to mathematical notation to support student explaining their thinking?

Part 2.

Does the textbook contain written-numeric meaning-making supports that clarify the steps in a method and/or help students carry out that step?

What are the written-numeric supports and how well do they support the mathematical ideas?

Part 3.

Language supports or issues

Does the formal mathematical vocabulary in a given language support or obscure its idea?

Are additional visual-quantitative or linguistic supports used for language that obscures a mathematical idea?

Part 4.

Does the textbook support a coherent student learning path to mathematically-desirable methods that are also made accessible to students?

To what extent is the learning path of student methods shown in the student book?

Does the order of problems support student learning (or at least not interfere with it)?

To what extent are the methods introduced in the student book mathematically desirable, i.e., they are general, show important mathematical features, and are efficient enough?

To what extent are the mathematically-desirable methods introduced in the student book made accessible to students? 
English this tens-structure is either not present (e.g., eleven, twelve), has the reference to ten changed phonetically (teen instead of ten) and is also reversed in order from the numerals (e.g., 14 has the 4 second but fourteen has the four first), and/or has the ones word phonetically changed (thirteen and fifteen instead of threeteen and fiveteen).

This linguistic difference makes it more difficult for English-speaking children to understand that teen numbers are composed of a ten and some ones (Ho \& Fuson, 1998; Miura et al. 1988). It also makes it more difficult to learn the advanced make-a-ten methods of single-digit addition and subtraction that are taught to first graders in China and other East Asian countries (Fuson \& Kwon, 1992a; Geary et al., 1993; Murata, 2004; Murata \& Fuson, 2001, 2006) and that depend on this understanding. In these methods, one addend (when adding, usually the smaller addend, and when subtracting, the unknown addend) is separated into the amount to make ten with the other addend and the amount to make the ones in the teen number. So $8+6$ is $8+2$ (is ten) +4 (the rest of the 6$)=10+4=14$. Essentially any problem is changed to a $10+n$ problem by giving some of one addend to the other addend to make a ten. This method is facilitated in Chinese and other East Asian languages because $10+4$ is said as ten four. It requires another step in English, where a child might write 14 thinking (ten and four) but still has to do the extra translation into English words (Oh yes, ten and four is fourteen.).

There are three conceptual prerequisites for the make-aten methods (see also Murata, 2004, for a discussion of how these are taught in a Japanese classroom). The prerequisites are easier to discuss if we introduce terminology used in the US Math Expressions program. Two addends that compose a number are called partners (e.g., in the make-a-ten method above for $8+6,8$ and 2 are partners of 10 , and 2 and 4 are partners of 6 ). To carry out the addition or subtraction make-a-ten methods, children must

(a) know the partners to ten for the numbers 9, 8, 7, and 6 to do the first step,

(b) know all of the partners of a given number to find the second step, and

(c) know the total $10+n$ composed to be written as $1 \mathrm{n}$ (or know that $1 \mathrm{n}$ decomposes to be $10+n$ ).

Step (c) is the step that is very easy if you say the written teen number using ten (e.g., 12 is said as ten two), but more difficult in English where they are no cues that 12 is ten and two.

The make-a-ten methods are in the highest of three levels of single-digit addition and subtraction solutions found around the world (see Fig. 1). In the first Count All Level, children cannot conceptualize an addend as

\begin{tabular}{|c|c|c|}
\hline Levels & $8+6=14$ & $14-8=6$ \\
\hline $\begin{array}{l}\text { Level 1: } \\
\text { Count all }\end{array}$ & 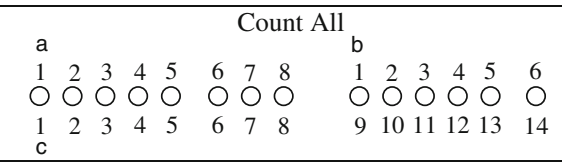 & 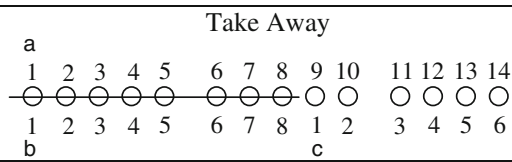 \\
\hline $\begin{array}{l}\text { Level 2: } \\
\text { Count on }\end{array}$ & 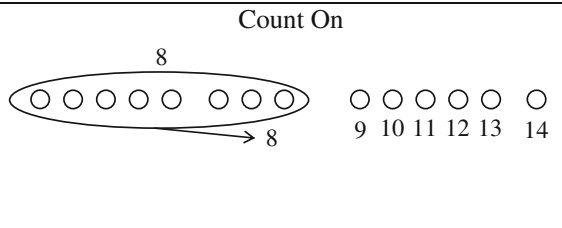 & To solve $14-8$ I count on $8+?=14$ \\
\hline $\begin{array}{l}\text { Level 3: } \\
\text { Recompose }\end{array}$ & Recompose: Make a Ten & $14-8:$ I make a ten for $8+?=14$ \\
\hline $\begin{array}{l}\text { Make a ten (general): } \\
\text { one addend breaks } \\
\text { apart to make } 10 \\
\text { with the other } \\
\text { addend }\end{array}$ & $\begin{array}{r}00000000 \quad 000000 \\
10+4\end{array}$ & 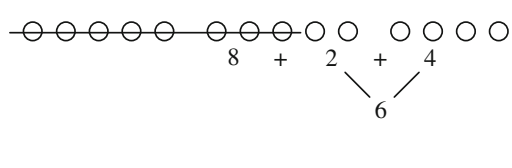 \\
\hline $\begin{array}{l}\text { Make a ten (from 5's } \\
\text { within each addend) }\end{array}$ & 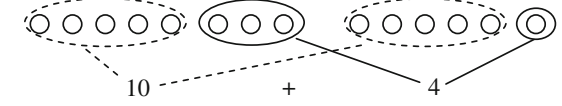 & $6=14$ \\
\hline Doubles $\pm n$ & $\begin{aligned} & 6+8=14 \\
= & 6+6+2 \\
= & 12+2=14\end{aligned}$ & \\
\hline
\end{tabular}

Note: Many children attempt to count down for subtraction, but counting down is difficult and error-prone.

Children are much more successful with counting on; it makes subtraction as easy as addition.

Fig. 1 Levels of children's addition and subtraction methods 
embedded within a total and must count each part of the addition or subtraction situation separately (count all or take away). In the second count on level, children can conceptualize the first addend as embedded within the total, begin with it, and count on to the total, keeping track of how many are counted on to find the total, if adding, or the unknown addend, if subtracting. In the third recomposing level, one or both of the addends are recomposed to make new addends, the total of which is already known. The make-a-ten methods are general and apply to all numbers. Using doubles is not a general method. It is widely used in the US but not in East Asia. Make-a-ten methods are taught and widely used in East Asia but not taught or used widely in the US.

\subsubsection{Learning supports in the Chinese books}

The Chinese books have several features that make them attractive to children. They are small $(15 \mathrm{~cm}$ by $21 \mathrm{~cm})$ and thin (122 pages in the first volume and 108 pages in the second volume). The pages are appealing and uncluttered, with many colored drawings of children or animals doing or being something mathematical. Unlike many texts in the US (but not Math Expressions), there is no art that is extraneous to the mathematical content. All of these features are typical for East Asian children's math books and not typical for math books in the US.

The third unit in the Grade 1 books is on the numbers 1-5. The translated title for this unit is Knowing the numbers 1-5, their addition and subtraction, and it covers pages 14-31. Children see cardinal numbers of things and associate these with a numeral, find such groups in realworld pictures, find partners (addends) of a number (see Fig. 2; such drawings will be called addend drawings from now on), see and represent addition and subtraction situations with equations and with addend drawings, and match visually to find more or less. The addend drawings summarize finding the partners, which is prerequisite (b) for the make-a-ten methods (see the above list of prerequisites). This activity is called How many with how many? (几和几). On a later page in the sixth unit, the direction for finding partners of ten is Find friends. Thus, the idea of the English word partners is consistent with the Chinese idea and might even be considered for use in their books. The word partners is used in Math Expressions because it engaged children and was powerful conceptually in permitting them to deal with the complex issue of two numbers embedded within a third number. Multiple methods are shown for addition and for subtraction. For an addition situation and equation $(4+1=5)$, pictures of three children are shown, each doing a different solution: counting all, counting on from 4 , and mentally picturing an addend drawing of 4 and 1 making an unknown total,

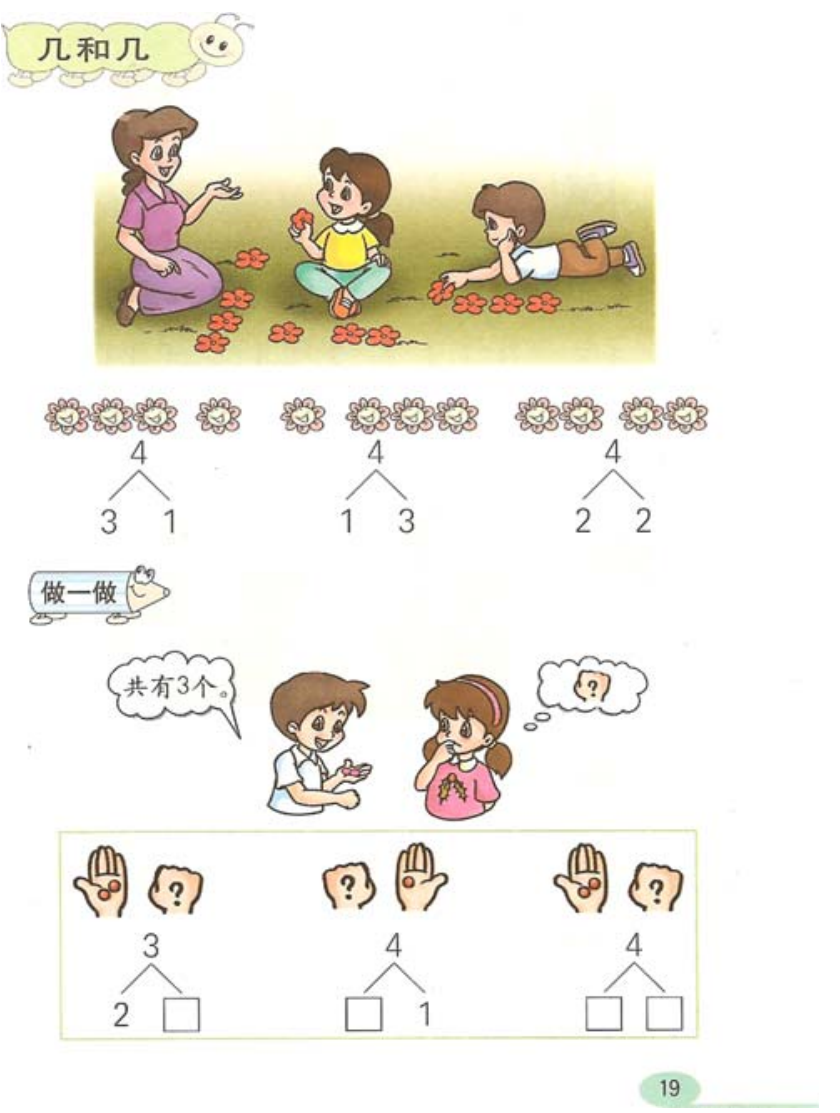

Fig. 2 Finding addends (partners) of a number

shown as a box. The three methods shown for a subtraction situation and equation $(5-2=3)$ are counting what is left, counting down 2 from $5(5,4,3)$, and mentally picturing an addend drawing of 2 and an unknown, shown as a box, making the total 5 on the top.

Children write numerals in very small spaces, smaller than a square centimeter. This is different from the US where young children typically write in considerably larger spaces. Some kindergarten and Grade 1 US teachers question the relatively small spaces for writing numerals in Math Expressions even though it is at least double that in the Chinese books. These relatively smaller spaces were chosen because some classroom research indicated that children having difficulty writing numerals could write small numerals more easily than the typical US larger numerals. Even though there is no research to support the use of larger writing spaces in the US, the strength of teacher beliefs about this did not permit the use in Math Expressions of spaces as small as typical in East Asian books. The result is that fewer examples can be used in the US with the larger font size.

The sixth unit focuses on numbers 6-10. This unit is translated as Knowing the numbers $6-10$, their addition and subtraction and covers pages 42-83. As in other East 
Asian books, these numbers are shown as rows or groups but also in 5-groups so that $6,7,8,9$, and 10 can be easily seen as $5+1,5+2,5+3,5+4$, and $5+5$. These visualizations help with adding and subtracting and especially with the make-a-ten methods. Children find all of the pairs of addends for each number and record them in addend drawings. Addition equations are related to subtraction equations, to such addend drawings, and to pictures of totals separated into addends (by color or space or both). Then without supportive drawings (but possibly/ probably with objects available to children), children fill numbers into addend drawings (either the total or the addend is the unknown) and into addition and subtraction equations (finding the unknown result on the right hand side of the equations). Children work deeply with each number. They find and represent relationships among the addends for that number within addition, subtraction, more/ less than, and addend drawing contexts. Math seems easy and interesting. Page 66 (see Fig. 3) shows the 5-groups and how this visual-quantity support can help children find the addend to make ten, which is prerequisite (a) for the make-a-ten methods. At the top page 66 also shows the
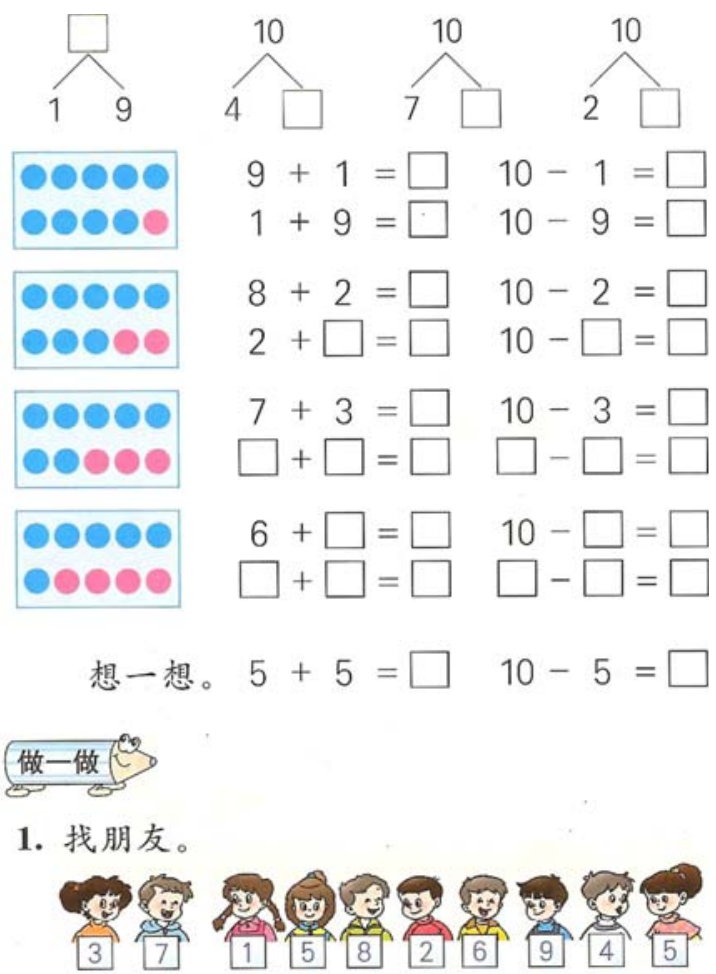

2.
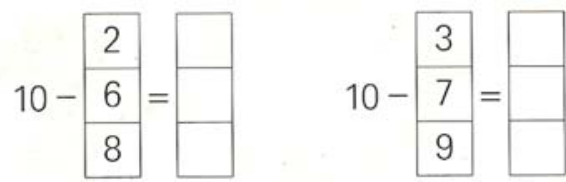

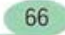

Fig. 3 Five groups and partners of ten addend drawings to ten and related addition and subtraction sentences for each pair of addends.

Chinese children have for a long time in Units 3 and 6 been finding an unknown addend within the addend drawings (see Fig. 2). On page 70 they continue this focus on prerequisite (b) for the make-a-ten methods by filling in the unknown addend in an equation. Visual real-world contexts such as seven pens in a box that clearly holds ten pens are paired with equations of the form $7+()=10$.

Then six pages lead children through successive additions or subtractions (or both) involving three numbers. Children must carry out such successive steps when doing the make-a-ten methods (but they will also have to generate the second and third numbers themselves in those methods). No parentheses are used, and operations are carried out left to right. For example, $5+2+1=8$ is solved as $7+1=8,8-2-2$ is solved as $6-2=4$, and $4-2+3$ is solved as $2+3=5$. Six review pages follow that show various activities for reflecting on patterns across addition and subtraction and for practicing finding addends of a number, adding, and subtracting.

Unit 7 focuses on the numbers $11-20$ as tens and ones (as a short-cut term, we will call the numbers 11-20 the teen numbers throughout the paper). This unit is called Knowing the numbers 11-20 and covers pages 84-90. The ten and left-over ones are shown in various ways, but especially as a bundle of ten sticks and some loose sticks (children in some East Asian countries use such small plastic sticks to make numbers to 100 as groups of tens and ones). Children write equations to show the tens and ones in the teen numbers: $10+3=13,3+10=13,13-3=10,13-10=3$. Understanding the ten in teen numbers is prerequisite (c) for the make-a-ten methods.

On page 88 in this unit the math terms for the parts of addition and subtraction equations are first introduced. They are more meaningful than are the English words addend, addend, sum and minuend, subtrahend, difference which come from Latin words and thus have little meaning today for English-speaking children. The first Chinese character (被) for the first addition or subtraction term means literally to be ()-ed by (or from) and the two characters (加/减数) for the second term mean addition (or subtraction) number. So these terms convey a change action situation that is lost in the English meanings: To be added to + adding number or To be subtracted from subtracting number. The English words for subtraction (i.e., minuend, subtrahend) are so meaningless that Math Expressions typically uses the words for addition in subtraction contexts (e.g., in $13-9=4,13$ is called the total and 9 and 4 are called the addends). This also helps children relate addition to subtraction (difference is taught for comparison situations, and the formal subtraction terms are taught but not used all the time in classroom discourse). 
Unit 9 supports the learning of addition of single-digit numbers to make teen totals (11-18). This unit is called Addition with carrying within 20 and covers pages 96-115. The first two pages show children in groups doing various enjoyable outdoor activities. One group is finding out how many 9 and 4 are. The 9 things are shown as two rows of five inside a box with one missing on one row. The 4 things are sitting next to the box. So one can easily visualize putting one of the 4 things inside the box to make 10 and 3 , which is 13. Three children tell how they find out how many. They demonstrate the three levels of addition solutions: One counts all from 1 to 13 , one counts on from 9 to $13(9,10,11,12,13)$, and one makes the group of ten, saying, "Put in one box first to get $10,10+3$ gets 13." The next page (see Fig. 4) shows various $9+n$ problems with different kinds of objects arranged in 5-groups so that the one thing that 9 needs to make 10 is clear. A sketch uses the addend drawing under the number added to 9 and shows how the 1 goes with the 9 to make 10 (see the top of Fig. 4). The problems at the top say, "Try it with such manipulatives and calculate." The characters on the pencil say, "Try it." The directions for \#1 say, "Circle them and calculate." All of these visual-quantitative and writtennumeric supports help children recompose the $9+n$ problem to be a $10+n-1$ problem, which is much easier to solve.

Thus, this page moves students from working with objects to working with drawings to understand the makea-ten method that is shown numerically at the top using addend drawings.

The first seven pages of this unit on the make-a-ten method for teen addition focus on problems with $9+n$, where $n=2$ to 9 . These are the easiest problems for the make-a-ten strategy because it is simple to see the first step: 9 needs 1 to make ten, so children only need to find the addends 1 and something for the number that is added. Seven more pages focus on the make-a-ten method with the first number 8,7 , or 6 . These require 2,3 , or 4 to make ten, and consequently the separation of the second number into that addend plus another is more difficult than for the problems with 9. The last of these seven pages has unknown addend problems such as $8+()=12$ and $9+()=15$. These lead into the make-a-ten strategies for subtraction (a later unit) if you think of subtraction as finding an unknown addend. The next two pages of the unit focus on problems that start with 5, 4, 3, 2 in totals of 11 or more. Problems are written in pairs to emphasize the use of commutativity, which has been developed several times in earlier units. The final four pages review various aspects of the unit.

Unit 2 in the second book for Grade 1 focuses on makea-ten strategies for problems with a total from 11 to 18 and two single-digit addends. This unit is called Subtracting

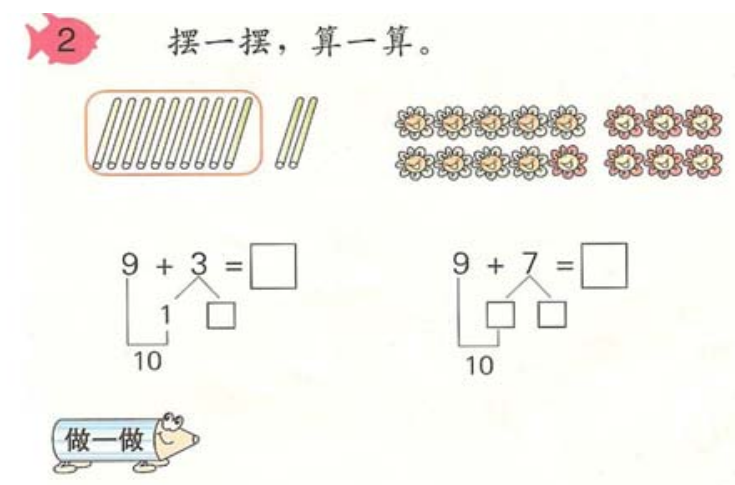

1. 圈一圈, 算一算。
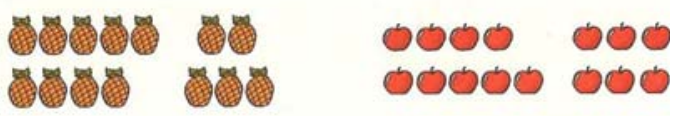

$9+5=\square$

$9+6=\square$

2.
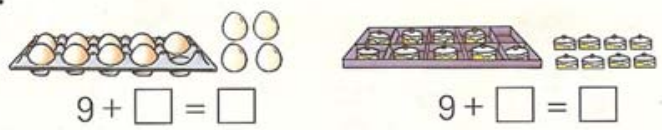

3. $9+5=$

$9+2=$

$9+9=$

$9+4=$

$9+8=$

$9+6=$

$9+7=$

$9+3=$

\section{8}

Fig. 4 Object and drawing supports for the make-a-ten method

with decomposing (a higher unit) within 20 and covers pages 10 to 26. Subtraction is solved in two ways: as an unknown addend using the make-a-ten strategy or taking the known addend from the ten in the teen total. So $12-9=$ ? can be solved by thinking " $9+?=12,9+1$ is ten and 2 more in the 12 , so $9+3=12$." Or it can be solved by thinking 12 is 10 and 2 , take the 9 from the 10 , leaving 1 , which added to the 2 makes 3 . These are close to the same processes, and either may use the visual representation of 9 within the whole ten two (10 and 2 things) or focus on the numerals 12 seen as 10 and 2 . The first five pages focus on problems that subtract 9, but then generalize to all subtractions from teen totals. Pairs or triplets (e.g., $3+8=, 11-3=, 11-8=$ ) of related problems are written to underscore the relationships between addition and subtraction.

\subsubsection{Learning supports in the US math expressions program}

The first author developed and fine-tuned this program over a period of extensive work in classroom and with teachers over 14 years; the early years of this work were within the 
Children's Math Worlds Research Project. The widespread view of single-digit addition and subtraction learning during those early years was that such learning started with concrete solutions, and children used pictures in the textbooks or manipulatives to do Level 1 count all or take away methods. However, then they moved directly to memorized facts. There was little notion in textbooks of the levels of children's methods shown in Fig. 1. US children actually carried these out but often literally under the table so that teachers could not see their fingers. Now more programs help children learn the Level 2 and Level 3 methods, but none has as systematic approach as outlined here for Math Expressions. Some programs explicitly refuse to teach any strategies to children, though they may support these informally.

Earlier research had indicated that most US first graders could learn to do the Level 2 counting on methods by the same time in the year as Chinese students learn the make-aten methods (e.g., Fuson \& Fuson 1992), so counting on was taught early in Grade 1. Children in Math Expressions initially made math drawings of circles or used fingers for Level 1 adding and subtracting small numbers, as shown in Fig. 1. Advancing to Level 2 counting on then involved: (1) being able to embed the first addend within the total, (2) abbreviating the count of the first addend to its last number, and (3) counting on from there. Children discussed how they could begin this final count of the total with the first addend number, as shown in Fig. 1. Most children kept track of how many counted on with their fingers (see the right side of Fig. 1). Learning to count on to find an unknown addend for subtraction was an important advance in the US where most children invent counting down, which is slow and prone to errors (Fuson \& Willis 1988). This forward subtraction method was even easier than was counting on for addition because students just need to monitor the word they say until they hear the total (e.g., for $8+?=14$, listen for 14) rather than feeling or seeing the known addend on fingers for addition (e.g., waiting for 6 on their fingers when adding $8+6)$.

Finding partners of numbers (e.g., 5 is made of 3 and 2 or of 4 and 1) facilitated the embedding of the addends within the total that was required to move to counting on. First graders in the first unit of Math Expressions separated rows of circles in a rectangle into partners by drawing a vertical line and recorded these as addends (e.g., as $3+1$ ). Because we found that many kindergarten and first grade children had difficulty writing equations (confusing the + , ,$-=$ symbols), children first only wrote the operational part of the sentence (e.g., $3+1$ or $4-3$ ). The teacher wrote full equations. In both Kindergarten and Grade 1 the first equation children saw was of the form $4=1+3$, which was used to record partners. This was done partly because extensive data indicate that US students think that equations have to have only one number (the answer) on the right side. Early experience finding the partners hiding inside a number and having the teacher record all of these with equations having the total on the left allowed students to feel comfortable with various forms of equations. Addition was recorded in the usual equations with the total on the right (e.g., $1+3=4$ ).

Partners were shown initially in the CMW program with a static part-part-whole drawing (Fuson \& Willis 1989) like those commonly used in the US (a rectangle with a horizontal line splitting it in half, and one of these halves further split by a vertical line). But children viewed these as static, and many did not understand why there were twice as many entities as were actually in the problem situation (because the total and both addends were there at the same time). The visual equal split for the addends in this representation was also problematic for some children because the addends were usually not the same. We began using a drawing like the addend drawing in the Chinese books and only later saw it in East Asian books. We called this a math mountain, with a story about tiny tumblers who lived at the top of a mountain and some went to play each day on one side of the mountain. In kindergarten children drew circles to show how many played on each side and then wrote these partners of the total at the bottom. These math mountains were introduced in Grade 1 in the third unit to represent unknown addends (partners), which were then related to subtraction situations. So partners/totals, addition, and subtraction situations and representations became related in problem solving as children used equations, or math drawings with circles, or math mountains to show their situations and solutions. The math mountains had a sensory-motor component that allowed children to compose/decompose the number from the total at the top to addends at the bottom, and children found this to be a powerful representation.

There was time in kindergarten to develop all three of the prerequisites for the make-a-ten methods (see Sect. 3.1.1). The East Asian 5-group patterns were used throughout the year. Children saw every day in the front of the room a chart called the Number Parade with the numbers 1 to 10 and dots above them. The numbers 1 to 5 had that many dots in a row, and the numbers 6 to 10 had the 5-group patterns ( 6 was a row of 5 with 1 below, 7 was a row of 5 with 2 below, etc.). Children later in the year practiced the partners of ten using this visual representation and the math mountains. Prerequisite (b) is knowing the partners to ten for the numbers $9,8,7$, and 6 . This was developed as outlined above and practiced in various ways.

Prerequisite (c), the concept of the ten in teens, was developed initially by using penny strips that showed a column of ten pennies (separated by a space so you could see two groups of five pennies). Children also rearranged 
groups of pennies into a column of ten pennies (which looked like the written 1 in the teen numbers) and the leftover pennies. Later they made successive teen numbers on a teen board using tens and loose ones. Children also used Secret Code Cards that showed the teen numbers such as 12 as 10 and 2: The 10 tile was twice as wide as the ones tiles, and the ones tiles were placed on top of the 0 in the 10 . Tiny numbers in the top left corner showed this large 12 as 10 and 2 (see Fig. 5 for 3-digit cards). Children also saw and wrote teen equations such as $15=10+5$. As soon as teen numbers were introduced children used both English words for numbers and tens and ones words that were expanded forms of East Asian words in which the ones were explicitly stated: 12 was said as twelve and as one ten two ones (the East Asian form is just one ten two). These experiences enabled even low SES half-day children to show concepts of tens and ones as do East Asian children on the Miura tasks (Fuson, 2009b). The press of the content of first-grade material did not give sufficient time to develop all of the prerequisites fully, though some time was spent on making partners to prepare for counting on, as discussed above. The make-a-ten methods were discussed later in the Grade 1 year to help more children use these methods.

The need for such extensive development of the tens in teens for US children was underscored for the first author in some early research on counting on. Most Grade 1 children readily learned to count on to find single-digit totals over ten, e.g., they found $9+5$ to be fourteen. But they did not know how to write fourteen or how many ones past ten fourteen was. They would write down the 1 in the tens place and then count using fingers eleven, twelve,
Fig. 5 Early multiunit conceptions and learning supports

Meanings for Drawings

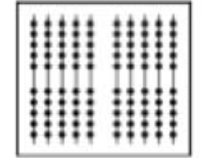

Ten tens and one hundred ones

MATH DRAWINGS

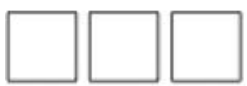

Three hundreds seven tens nine ones

QUANTITY WORDS
Sequence Multiunit Conception Count the quantities by multiunit English named values within an accumulating sequence total: Count by hundreds, then tens, and then ones, shifting the count to each new multiunit: $100,200,300$, (shift to tens) $310,320,330,340,350,360,370$, (shift to ones) $371,372,373,374,375,376$, 377. 378.379

Separate Multiunit Conception Count (see) the multiunit quantities hundreds, tens, and ones

\section{Multiunit Quantities}

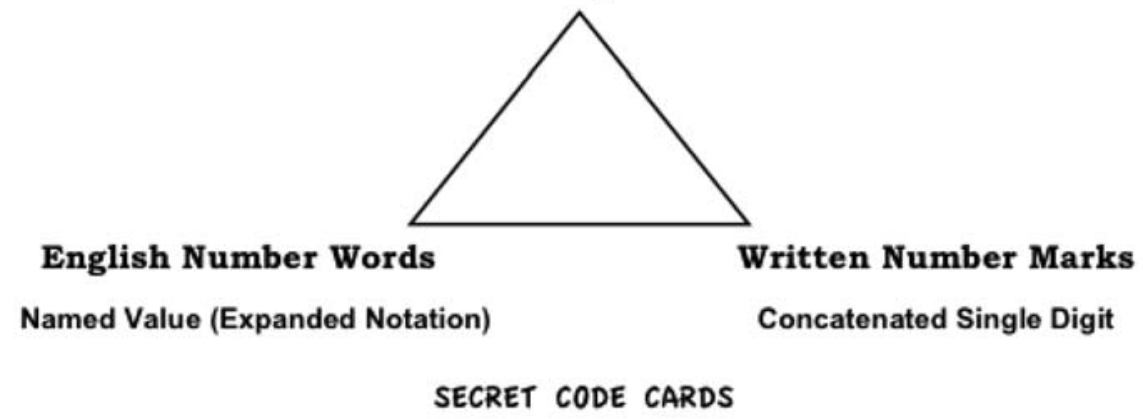

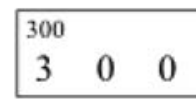

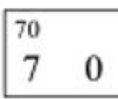

300

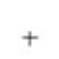

70

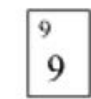

9

nine

Learn the repeating cycles in the English counting sequence

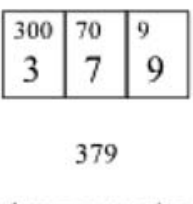

three seven nine 
thirteen, fourteen, see four fingers up, and write 4 in the ones place.

The unitary nature of the count sequence in English (nothing noticeable happens going past ten “... nine, ten, eleven, twelve, ..." as it does in Chinese where one says "... nine, ten, ten one, ten two, ten three, ...") made it so easy to continue counting on that many children in Math Expressions did not make the effort to shift to using the make-a-ten strategy. This strategy is more difficult in English because of the irregular nature of these teen words. In some Math Expressions classes the majority of children did become fluent in the make-a-ten strategy, but in many other classes this did not happen until Grade 2, when its use in multidigit addition and subtraction was helpful because you actually needed to think of the teen numbers as a ten and some ones in that context. Ma (1999) reported that Chinese teachers felt that the makea-ten method was the first example of multidigit adding and subtracting, which was then used and generalized to larger numbers. This is clear in the titles reported above for these units: Addition with carrying within 20 and subtraction with decomposing (a higher unit) within 20. In most programs in the US there is no sense that the single-digit computations with teen totals have anything to do with multidigit addition and subtraction. They are either viewed as stimuli to be memorized rotely or as problems more difficult for children to solve than totals to ten because children cannot show the teen totals on their fingers, which moves many US children to begin to count on. For US children the lack of a cultural press toward the make-a-ten methods, and its greater difficulty in English, meant that beginning to use these methods was actually a later step within multidigit addition and subtraction rather than the first step, as for Chinese children. In the future, as more US teachers come to understand the learning path of the levels of addition and subtraction in Fig. 1 and the power of the make-a-ten methods, enough time might be spent on them for more students to become fluent with them. However, counting on is rapid and accurate enough for those students who cannot handle the multiple mental steps in the make-a-ten strategies.

\subsection{Multidigit addition and subtraction}

\subsubsection{Language issues in understanding place value notation}

The teen difficulties in English extend to all of the numbers under 100. English (as well as other European languages) does not explicitly name the tens for numbers from 20 to 99, though it does name the hundreds and thousands. Thus, one says 4562 as four thousand five hundred sixty-two rather than as six ten (60) as in Chinese. This makes it more difficult for children speaking English to understand the quantities in 2-digit numbers as tens and ones (Miura et al. 1988; Fuson \& Kwon, 1992b) and therefore to understand computational methods involving 2-digit addition and subtraction. The fact that ordinarily few US children learn the ten-structured methods for addition and subtracting described above also means that many more are dependent on single-digit methods that do not involve ten when finding single-digit sums or differences within multi-digit computations.

Figure 5 shows the aspects of multiunit quantities, number words, and written number marks that children in all countries must learn to understand and connect. The multiunit quantity meanings are the same in all countries, and the same written number marks are now used in most countries. But the structure of the number words varies considerably. English-speaking children must construct a sequence multiunit conception that creates a quantity by counting it up (accumulating it) in units of hundreds, tens, and ones; this conception arises from the counting patterns in English words, and especially in the decade words for tens that refer to thirty or sixty or eighty ones, not 3 or 6 or 8 groups of ten. But children from any country can also see multiunit quantities as in the math drawing on the upper left: They can see 3 multiunits of a hundred, seven multiunits of ten, and nine single units. These are easier to see if the quantities are drawn using 5-groups as in Fig. 5. The secret-code cards (that show the "secret code of the numbers") mentioned above for the teens are shown here. These allow children to understand the written number marks both as positional referents to the multiunit quantities and as expanded notation that shows the English named values of collections of units. In Chinese, the learning task is simpler because the quantity words are almost the Chinese counting number words. Children do need to relate these quantities to the positions in the written number marks, but marks such as 79 are less likely to be considered as just the concatenated single digits 7 and 9 when they are said as seven ten nine than when they are said as seventy nine.

East Asian books all show the meanings of place-value notation using quantities such as bundled sticks or base-ten blocks, and they use such pictures to show such quantities as they relate to the steps of multidigit addition and subtraction. Many US texts now also show such pictures, especially base-ten blocks in which the ones are $1 \mathrm{~cm}^{2}$, the tens are $10 \mathrm{~cm}$ long, and the hundreds are a flat that is 10 by 10 by $1 \mathrm{~cm}$. Many US texts now also show these blocks or other quantities with multidigit addition and subtraction, but usually not in separate steps. In the research leading to Math Expressions, we found that schools seldom had enough blocks or other multiunit quantities for children to 
use, such manipulatives created management issues, and they were hard to show to the whole class when explaining multidigit addition and subtraction. Therefore we moved to using math drawings like those shown in Fig. 5. Students first made the 10-sticks and 100-squares on centimeter dot grids and then moved to making sketches (the math drawings) using the quick-tens and quick-hundreds using 5 -groups so that a viewer could see at a glance how many there were. This also reduced drawing errors considerably and increased the use of the separate multiunit conception that did not require counting by hundreds, tens, and ones. Each step in a written multidigit addition and subtraction method could be related to a step in the drawing during explanations of methods. When explaining their method, children used the quantity words that named the multiunits (three hundreds seven tens nine ones) that were like Chinese number words (except for the plurals and the word ones at the end), and they also became able to use English number words. They initially made numbers using secretcode-cards, which had drawings of hundreds, tens, and ones on the back, and sometimes used these when solving problems.

\subsubsection{Multidigit addition methods}

The national context in the US during the Children's Math Worlds Research Project was predominantly one of two extremes. One was that students were taught a mathematically-desirable method (see New Groups Above in the middle of Fig. 6), but often with little explanation from the teacher or the book, which might show one drawing of ten ones making one ten. So this mathematically-desirable method was not made accessible to students. In reaction to this meaningless approach, several projects focused on children inventing methods for 2-digit addition (e.g., Cobb 1987; the projects summarized in Fuson, Wearne, et al., 1997). These invented methods were accessible but often were not mathematically-desirable. They often involved counting by tens and ones and did not generalize easily to larger numbers (counting on by hundreds, tens, and ones took considerably longer than did the 2-digit methods), and these 3-digit methods involved counting over a hundred, which was a bit challenging. These methods were even more complex for larger numbers. As discussed in Fuson and Murata (2007), the classroom research that culminated in Math Expressions began a search for written-numeric multidigit methods that were mathematically-desirable (were general, showed important mathematical features, and were efficient enough) but were also accessible to children, i.e., easier than the abstract and non-helpful methods currently taught in the US. Two such mathematically-desirable and accessible methods were identified for addition, and one method with left-to-right or right-to-left variations was identified for subtraction. All methods were invented by second graders using base-ten blocks to add and subtract 4digit numbers (Fuson \& Burghardt, 2003). We tried these methods in many different classrooms, and they appealed to teachers and to students. In many schools, base-ten blocks were not available and their use created management issues, so the project changed to using the math drawings in
Fig. 6 Multidigit addition methods
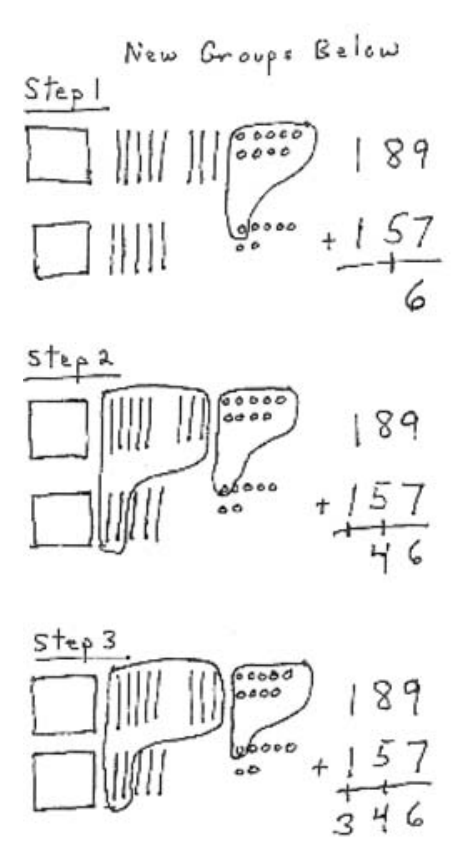
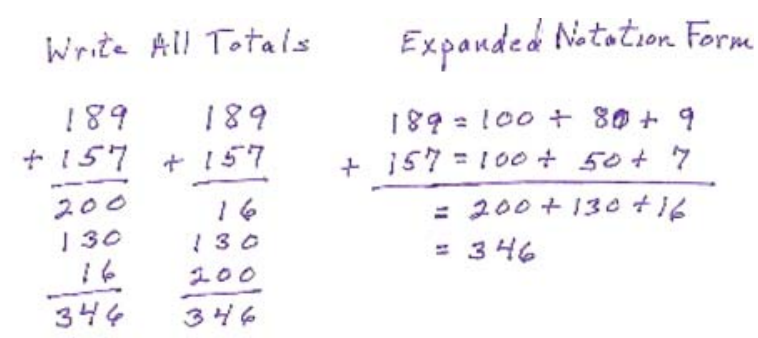
New Grovps Above
11
189
$+\frac{157}{346}$
Variations of New
Groups Below
$189+189$
$+\frac{157}{346}+\frac{157}{346}$
Mental New Groups
189 Right to Left
$+\frac{157}{346}$ Left to Rigkt

$$
\begin{aligned}
& \text { Easier New } \\
& \text { Groups Above } \\
& 29 \\
& \times 89 \\
& +157 \\
& \hline 346
\end{aligned}
$$


Figs. 6 and 7. Math drawings had many advantages over manipulatives (Fuson, Atler, Roedel, \& Zaccariello, 2009). Some students preferred each one of the mathematicallydesirable and accessible methods we identified, so we included both of them in Math Expressions. In Math Expressions children begin multidigit addition and subtraction by inventing their own methods using the math drawings in Figs. 6 and 7, but the mathematically-desirable and accessible methods are quickly introduced in story scenarios and discussed along with the current common method. Children are allowed to use any general method they can explain and relate to a math drawing. Students stop making a drawing when they can explain their method using quantity language to refer to the steps in the written numerals.

The two mathematically-desirable and accessible addition methods are the New Groups Below and the Write All Totals methods shown in Fig. 6. The math drawings given in Fig. 6 for each step in the New Groups Below method show how such drawings support both big ideas of multidigit adding: adding like multiunits (ones to ones, tens to tens, hundreds to hundreds) and what to do when you have ten or more of a given multiunit (make one or more new groups of a higher multiunit). One can also see five advantages of this method over the New Groups Above method shown in the middle of the page.

(a) When you write the new group below, it is near the ones of the teen number you made, so you can see the whole teen number more easily. This clarifies what you are actually doing when you make the new group and put it in the next left column. For example, when adding the 9 ones and 7 ones in Fig. 6, you can see the 16 much more easily in New Groups Below than in the New Groups Above method where the 1 and the 6 are separated so far.

(b) Having the whole teen number close together also makes it easier to write because students can write the 16 in order as 1 then 6 rather than writing the 6 ones below and then writing the 1 above the next-left column, as is usual.

(c) It is much easier to add the numbers whenever you have a new group because you add the two numbers you see in the problem (e.g., 8 tens and 5 tens in Fig. 6) to get 13 tens and then add the 1 ten waiting below to get 14 tens. In the New Groups Above method, you add the 1 to the top number 8 , hold that total 9 in your mind while you add to it the bottom number 5 (you can't even see the second number 9 and you can see the old top number 8 that you are no longer using). Or students may add the two numbers they see but forget to add the 1 on the top.

(d) It is easier to see multidigit addition as adding two whole (horizontal) multidigit addends, resulting in a (horizontal) multidigit total at the bottom.

(e) Some students object to the common US method of trading the new higher multiunit above the problem because they say that you are changing the problem. And in fact, trading the new higher multiunit above the problem does change the problem, because you are adding the new multiunit group into the top number as you go. New Group Below does not have this issue.

The two Write All Totals methods and the Expanded Notation Form shown at the top of Fig. 6 are variations of the second mathematically-desirable and accessible method
Fig. 7 Multidigit subtraction methods
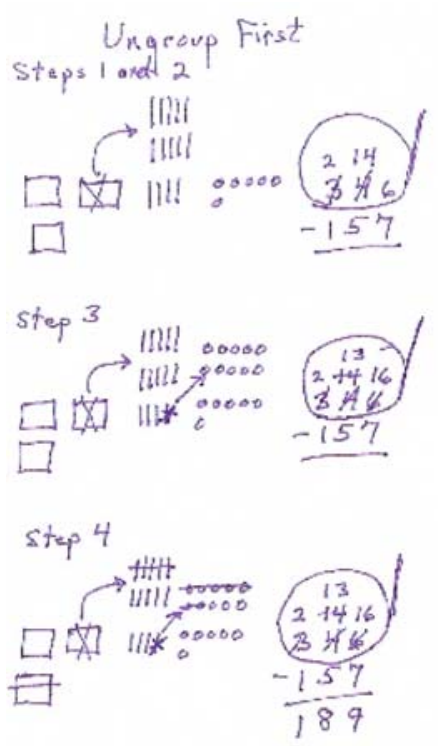
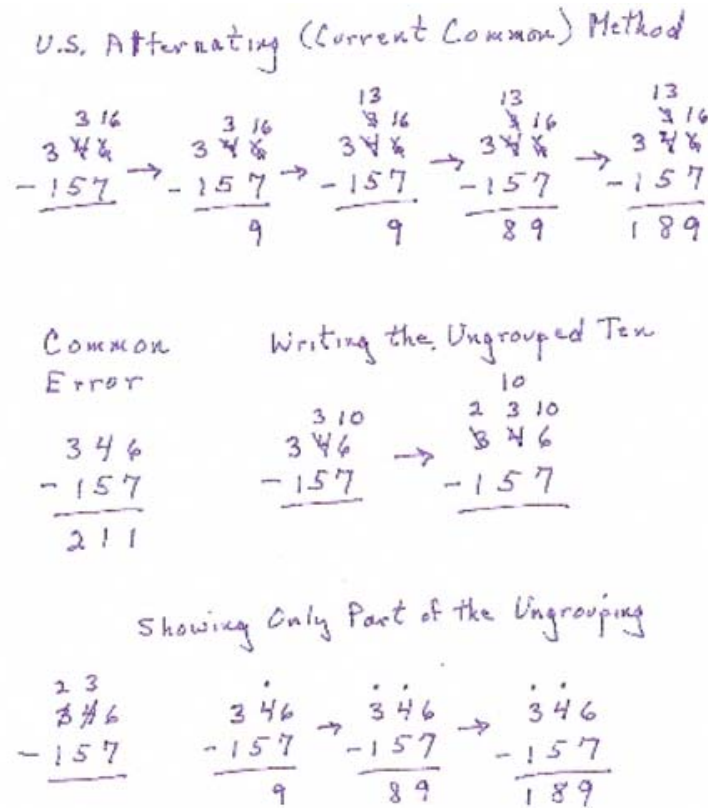
used in Math Expressions. This method can be shown by making both numbers with the secret-code cards and then taking apart the cards to show the numerical values using zeroes (see especially the top right example in Fig. 6). After using the secret-code cards, students become able to see the zeroes hiding under the tens and ones digits (e.g., they can see 80 and 50 in the vertical problems). Then they do not need to see or write out the expanded notation as in the top right but can do either one of the vertical methods. Many students prefer to work left to right (they read from left to right) and so use the left-to-right version, but some students use the right-to-left method. To keep these numerical methods meaningful, students connect each step in the numeric method to steps in the math drawing as they solve and explain their method to their classmates.

The New Groups Below and Write All Totals methods arose independently from research in US classrooms and not from East Asian books. But preparation of this paper indicated that both methods appear in East Asian books although the New Groups Below method is shown with the $1 \mathrm{~s}$ in a somewhat different place (see the right middle of Fig. 6). The Chinese books show the left variation of New Groups Below. One Japanese book shows the variation on the right. In the Math Expressions program we had tried different variations of where to write the new group and found that it was easiest for children to understand if it was written on the line, ready to be added in, and aligned exactly under the column for the new kind of multiunit it was. Chinese and Japanese children might also find it easier to write the new group below on the line "waiting for the other numbers to be added first". Another Japanese book showed manipulatives for the New Groups Above method, but did not record any new group: everything was done mentally. This was done right to left, but it can be done from the left to the right if you look ahead to the next-right column to see if its total will be ten or more, in which case you increase the total of the left column by one (this is a common mental method taught in European countries). At the bottom right is a method invented in our base-ten block study (Fuson \& Burghardt, 2003). This improves the New Groups Above method by simplifying the addition to the two given numbers and generalizes easily to larger numbers. We did not use this method in Math Expressions because we found that some children confused it with subtraction because you cross out a number. Korean books showed all three variations of the Write All Totals methods initially (including the Expanded Notation method) but then moved to the New Groups Above method.

The drawings in Fig. 6 show how the 5-groups in the drawings can support the make-a-ten method. The top left drawing shows that 9 needs 1 more to make ten; when that 1 is taken from the 7 it becomes 6 , making 1 ten and 6 . The 8 tens need 2 more tens to make 10 tens, leaving 3 tens, so this is ten and 3 of the tens (or thirteen tens) or one hundred thirty (then plus the one more ten is fourteen tens or one hundred forty).

\subsubsection{Multidigit subtraction methods}

Many students in the US make the error of subtracting the smaller number in a column from the larger number even if the smaller number is on the top (see the common error in the middle of Fig. 7 where $346-157=211$ ). This is the major reason US national performance on 2-digit subtraction is only $28 \%$ correct in Grade 2 , and this error remains extremely common clear into high school (e.g., literature reviewed in Fuson, 1990, and Fuson, Wearne, et al., 1997). The current common method in the US alternates the steps of ungrouping and subtracting (see the top right of Fig. 7). This contributes to such errors even for students who usually ungroup. For example, in the second step students see a 3 on the top and a 5 below and they have just subtracted the ones, so they are in subtraction mode. Two pops into their mind as the difference of 3 and 5, and they write 2 in the tens column.

The mathematically-desirable and accessible subtraction method used in Math Expressions eliminates the alternating steps by doing all necessary ungrouping first and then doing all of the subtracting. This approach has other benefits. Ungrouping the top number wherever needed also helps to emphasize that this number is one whole multidigit number that is being fixed to get it ready to have the second whole multidigit number subtracted from it. This conceptual point can be emphasized by a further visual support. We have students draw a magnifying glass around the top number. They draw an ellipse around the whole top number that is big enough to hold all of the ungrouping, with a little stick at the top right for the handle. The magnifying glass is introduced as something that reminds us to "look inside the top number" to check in each column to see if there is enough to subtract. This serves to inhibit the subtractsmaller-from-larger number error that is often made before students even think about ungrouping. This also makes a visual grouping that emphasizes the top multidigit number as a whole and thus facilitates a discussion about whether the value of the top number is changed when it is ungrouped. Because many US students view multidigit subtraction as successive vertical operations on columns of single digits, many think that ungrouping does change the value of the top number (e.g., see literature reviewed in Fuson, 1990). Students enjoy the metaphor of the looking glass, but they drop this step when they no longer need it. This method has the further advantage that both steps can be done in either direction, allowing the left-to-right approach preferred by many students (left-to-right ungrouping is shown in Fig. 7). Learning disabilities 
teachers have reported how well this method works with their students because it is so much easier for many learning disabled students to ungroup and subtract from the left and not to alternate steps. Students also have productive Math Talk in their classrooms as they discuss whether and why you can ungroup and subtract in either direction.

As with addition, the math drawings also help with both big ideas of subtraction: subtract like multiunits and ungroup within the top number when needed to get enough of the next-right multiunits. They also support the make-a-ten mental subtraction approaches. In Fig. 7, the 7 ones are taken from the ungrouped ten ones, leaving 3 ones to put with the 6 ones in 16. Similarly the 5 tens are taken from the ungrouped ten tens, leaving 5 tens to add to the 3 tens left in the top number. Students can then carry out these methods mentally by looking at the 1 in the 16 ones and the 13 tens and seeing it as 10 . Seeing the numeric 1 in the tens place as a ten (10) is facilitated by the Math Expressions secret-code cards, in which students can see the 0 hiding under the 6 ones. Because single-digit subtraction is usually approached as finding an unknown addend in Math Expressions, either counting on or the make-a-ten methods are likely to start with the number written in the second row (e.g., in the ones place in Fig. 7, go from 7 up to the 16 by counting on 9 or thinking 7 up to ten is 3 and 6 more is 9 . Some East Asian students might be helped by making math drawings for addition or for subtraction, though the supports in the language for the ideas may make this less necessary than for children speaking English.

The East Asian methods found in books typically are the alternating method shown at the top right but with differences in how this is shown. All initially show the steps paired with the unbundling or ungrouping of objects. In the Korean books and one Japanese book (see the middle right of Fig. 7: Writing the Ungrouped Ten), the ungrouped 10 is written above the column instead of writing the whole teen number (so 10 is above 6 rather than writing 16). This visual support facilitates the make-a-ten method because the bottom number can be taken from the 10 or thought of as finding the unknown addend: Seven and three make ten and the 6 ones that are there make 9 one (Fuson \& Kwon, 1992b). However, for US students who do not use this method of subtracting, writing the 10 might be confusing, so we did not use it. A Japanese book from a different published than the one described above just shows the left side of each ungrouping (the decrease by one) and the make-a-ten subtraction is done mentally (this is easy to do if one visualizes a 10 written above as in the Korean and Japanese methods). Fourth graders in the US have invented this short-cut, saying that they do not need to bother to write the teen number because they know it is there. The Chinese text shows even less of this ungrouping step, simply putting a dot above any column that gave a multiunit to the next right column. Therefore students must carry out the make-a-ten subtraction mentally with no support and also remember to reduce the difference by one after they find it for a column that has a dot above it. However, this dot method is introduced in the Chinese text with drawings of unbundling a group of ten sticks and writing the new unbundled names (4 and 16) above the 56 as well as showing the dot above the 5 .

\subsubsection{Three levels in multidigit addition and subtraction}

The three levels identified by Ma (1999) for Chinese teachers seemed to be verified in other East Asian books. The make-a-ten methods for teen addition and subtraction were developed in separate units as Level 1. In Level 2, multiple methods were given for 2-digit problems. In Level 3 for 3-digit and larger problems, the books focused on one generalizable mathematically-desirable method. However, not all East Asian students may be able to explain these larger problems fully. Fuson and Kwon (1992b) found that all students could explain the ungrouping in two-digit problems, but that some viewed three-digit problems only as columns of single digits and did not, for example, say they were dealing with tens when they explained their adding or subtracting in the tens column. Drawings and modeling by the teacher and other students do enable Math Expressions students to make such quantity explanations for larger numbers. However, when one is actually carrying out multidigit addition and subtraction, especially with larger numbers, it may be useful to ignore the names of the places and solve as if each column is the same kind of multiunit. The consistent ten-for-one trades between all adjacent columns including decimal places enables one to do this, and a student could add the name of the place if an explanation is desired.

\subsubsection{Organization of problems with and without regrouping}

The US has an issue that does not seem to occur in the East Asian books. Two-digit addition and subtraction problems without regrouping are introduced and practiced in Grade 1, and problems with regrouping are not experienced until almost a year later, in Grade 2. This sets up students for the top-from-bottom error in subtraction because they have already done many problems subtracting within each column. To a lesser extent, this also creates the error of writing addition totals with teen numbers in each column (i.e., doing no grouping). To avoid creating such errors, in Math Expressions problems with regrouping are introduced as the first multidigit addition and subtraction problems to students. Project first graders begin with two-digit problems with regrouping, which are accessible to them using math 
drawings (Fuson, Smith, \& Lo Cicero 1997). In Grade 2 the project initially used the common practice of giving twodigit problems with totals to 100 and then moving to general three-digit addition. But this step was too large; many students struggled with three-digit addition problems that had two groupings (from the ones and from the tens). However, they could fairly readily handle 2 regroupings when there was only 1 hundred (e.g., $89+57$ ). So a couple of days initially are spent on multidigit addition with 2-digit totals $\leq 100$ and then problems with totals $\leq 200$ are given. The step to general 3-digit addition with totals to 1,000 is then very simple for all students. The same approach is taken with subtraction, where the first problems given have zeroes in the tens and ones. This sets up students to do all of the ungroupings first, and avoided the common difficulty in the US of students finding these problems particularly difficult when they come last. In East Asian books a problem or problems with no regroupings are given first and then are followed by problems with regroupings (grouping in addition and ungrouping in subtraction).

\subsubsection{Language for regrouping}

Ma (1999) reports that many Chinese teachers stress the importance of the language the rate for composing a higher value unit (进率) as explaining the regrouping involved in multidigit addition and subtraction. We agree that the older terms borrowing and carrying that were used in the US and then used in China (Ma reports) are conceptually misleading because they imply that you are changing the number and borrow also implies that you will return it. However, in the literal translation for the Chinese characters (进位) this step in multidigit addition is moving up a place (i.e., composing a higher unit). This is procedural but also the $u p$ at least implicitly has the connotation of a higher value (i.e., the rate, 10). Multidigit subtraction is termed on the student page as moving back a place (退位), i.e., decomposing a higher unit). The Chinese terms used in multidigit addition and subtraction are consistent with its numbering system that highlights the place value in numbers and related computations.

Because the term regrouping was also used in the US, in Math Expressions, the term grouping was used for making a new multiunit group in multidigit addition, ungrouping for the reverse process in subtraction, and regrouping to describe both of these. Discussing how the trades between adjacent multiunits are the same ten-for-one trades across all adjacent columns lifts these regrouping processes to the higher general level intended in the language used by Chinese teachers (the rate for composing a higher value unit). In the US rate has strong multiplication/division connotations, so this word is not so appropriate. Regrouping (or composing/decomposing) fits addition/subtraction better.

\section{Conclusions}

This in-depth analysis of the major early numerical aspects in a representative Chinese textbook series and a US textbook series with major East Asian components illustrates how linguistic issues create different teaching and learning tasks for the same mathematical topic. Previous analyses of East Asian textbooks have emphasized their coherence and the power of their meaning-making supports. This article indicates that a program in the US can have a similar coherence and power, but that additional visual-quantitative and linguistic supports are needed to compensate for the linguistic complexities that are not present in China.

We also saw that the final mathematically-desirable method emphasized in different East Asian books (even within the same country) varies considerably in the writtennumeric supports within it and thus in its accessibility to students. Some methods support some steps, while others support few or no steps. We also saw that the accessibility of a mathematically-desirable method (the make-a-ten method) can vary with the language, requiring an extra step in English. When it is simple to make a method accessible as well as mathematically desirable, it seems desirable to choose methods to teach to all students that are both mathematically-desirable and accessible, or that can be made accessible with extra learning supports.

Acknowledgments The first author wishes to thank all of the teachers and students with whom she has worked in the classroom research underlying this paper. That classroom research was partially funded by National Science Foundation Grant Numbers ESI-9816320, RED-935373 and REC-9806020. Any opinions, findings, and conclusions or recommendations expressed in this paper are those of the author and do not necessarily reflect the view of the National Science Foundation. We would also like to thank three reviewers and the journal editor for their thoughtful comments on a prior version of this article.

Open Access This article is distributed under the terms of the Creative Commons Attribution Noncommercial License which permits any noncommercial use, distribution, and reproduction in any medium, provided the original author(s) and source are credited.

\section{References}

Cai, J. (2008). Some highlights of the similarities and differences in intended, planned/implemented, and achieved curricula between China and the United States. In Z. Usiskin \& E. Willmore (Eds.), Mathematics curriculum in Pacific Rim countries: China, Japan, Korea, and Singapore (pp. 157-181). Charlotte: Information Age Publishing.

Chen, X., \& Li, Y. (2008). Language proficiency and mathematics learning. School Science and Mathematics, 108, 90-93.

Cobb, P. (1987). An analysis of three models of early number development. Journal for Research in Mathematics Education, 18, 163-179. doi:10.2307/749054. 
Division of Elementary Mathematics. (2007). Nine-year compulsory education curriculum standards-based mathematics textbooks, grade 1: Vol. 1. Beijing: People's Education Press.

Fuson, K. C. (1990). Conceptual structures for multiunit numbers: Implications for learning and teaching multidigit addition, subtraction, and place value. Cognition and Instruction, 7, 343-403. doi:10.1207/s1532690xci0704_4.

Fuson, K. C. (2006, 2009a). Math Expressions, Grades K, 1, 2, 3, 4, 5. Boston: Houghton Mifflin Harcourt Publishers.

Fuson, K. C. (2009b). Helping U.S. disadvantaged kindergarten children understand place value like East Asian children. Paper given at the Annual Conference of the National Council of Teachers of Mathematics, Washington, DC.

Fuson, K. C., Atler, T., Roedel, S., \& Zaccariello, J. (2009). Building a nurturing, visual, Math-Talk teaching-learning community to support learning by English Language Learners and students from backgrounds of poverty. New England Mathematics Journal, in press.

Fuson, K. C., \& Burghardt, B. H. (2003). Multi-digit addition and subtraction methods invented in small groups and teacher support of problem solving and reflection. In A. Baroody \& A. Dowker (Eds.), The development of arithmetic concepts and skills: Constructing adaptive expertise (pp. 267-304). Hillsdale: Erlbaum.

Fuson, K. C., \& Fuson, A. M. (1992). Instruction to support children's counting on for addition and counting up for subtraction. Journal for Research in Mathematics Education, 23, 72-78. doi:10.2307/ 749165.

Fuson, K. C., \& Kwon, Y. (1992a). Korean children's single-digit addition and subtraction: Numbers structured by ten. Journal for Research in Mathematics Education, 23, 148-165. doi:10.2307/ 749498.

Fuson, K. C., \& Kwon, Y. (1992b). Korean children's understanding of multidigit addition and subtraction. Child Development, 63, 491-506. doi:10.2307/1131494.

Fuson, K. C, \& Murata, A. (2007). Integrating NRC principles and the NCTM Process Standards to form a Class Learning Path Model that individualizes within whole-class activities. National Council of Supervisors of Mathematics Journal of Mathematics Education Leadership, 10(1), 72-91.

Fuson, K. C., Smith, S. T., \& Lo Cicero, A. (1997a). Supporting Latino first graders' ten-structured thinking in urban classrooms. Journal for Research in Mathematics Education, 28, 738-766. doi: $10.2307 / 749640$.

Fuson, K. C., Wearne, D., Hiebert, J., Human, P., Murray, H., Olivier, A., et al. (1997b). Children's conceptual structures for multidigit numbers at work in addition and subtraction. Journal for Research in Mathematics Education, 28, 130-162. doi:10.2307/ 749759.

Fuson, K. C., \& Willis, G. B. (1988). Subtracting by counting up: More evidence. Journal for Research in Mathematics Education, 19, 402-420. doi:10.2307/749174.

Fuson, K. C., \& Willis, G. B. (1989). Second graders' use of schematic drawings in solving addition and subtraction word problems. Journal of Educational Psychology, 81, 514-520. doi: 10.1037/0022-0663.81.4.514.

Garner, R., Brown, R., Sanders, S., \& Menke, D. J. (1992). "Seductive details" and learning from text. In K. A. Menninger,
S. Hide, \& A. Krupp (Eds.), The role of interest in learning and development (pp. 239-254). Hillsdale, NJ: Erlbaum.

Geary, D. C., Bow-Thomas, C. C., Fan, L., \& Siegler, R. S. (1993). Even before formal instruction, Chinese children outperform American children in mental addition. Cognitive Development, $8,517-529$.

Ho, C. S., \& Fuson, K. C. (1998). Effects of language characteristics on children's knowledge of teens quantities as tens and ones: Comparisons of Chinese, British, and American kindergartners. Journal of Educational Psychology, 90, 536-544. doi:10.1037/ 0022-0663.90.3.536.

Levie, W. H., \& Lentz, R. (1982). Effects of text illustrations: A review of research. Educational Communication and Technology Journal, 30, 195-232.

Li, Y. (2007a). Curriculum research to improve teaching and learning. School Science and Mathematics, 107, 166-168.

Li, Y. (2007b). Curriculum and culture: An exploratory examination of mathematics curriculum materials in their system and cultural contexts. The Mathematics Educator, 10(1), 21-38.

$\mathrm{Li}$, Y. (2008). What do students need to learn about division of fractions? Mathematics Teaching in the Middle School, 13, 546552.

Ma, L. (1999). Knowing and teaching elementary mathematics: Teachers' understanding of fundamental mathematics in China and the United States. Mahwah: Lawrence Erlbaum Associates.

Mayer, R. E., Sims, V., \& Tajika, H. (1995). A comparison of how textbooks teach mathematical problem solving in Japan and the United States. American Educational Research Journal, 32, 443-460.

Miura, I., Kim, C. C., Chang, C., \& Okamoto, Y. (1988). Effects of language characteristics on children's cognitive representation of number: Cross-national comparisons. Child Development, 59, 1445-1450. doi:10.2307/1130659.

Murata, A. (2004). Paths to learning ten-structured understanding of teen sums: Addition solution methods of Japanese Grade 1 students. Cognition and Instruction, 22, 185-218. doi:10.1207/ s1532690xci2202_2.

Murata, A. (2008). Mathematics teaching and learning as a mediating process: The case of tape diagrams. Mathematical Thinking and Learning, 10, 374-406. doi:10.1080/10986060802291642.

Murata, A., \& Fuson, K. (2001). Learning paths to 5- and 10-structured understanding of quantity: Addition and subtraction solution strategies of Japanese children. In R. Speiser, C. S. Maher, \& C. Walter (Eds.), Proceedings of the twenty-third annual meeting of the North American chapter of the international group for the psychology of mathematics education: Vol. 2 (pp. 639-646). Columbus: ERIC Clearinghouse for Science. and Environmental Education: Mathematics.

Murata, A., \& Fuson, K. (2006). Teaching as assisting individual constructive paths within an interdependent class learning zone: Japanese first graders learning to add using ten. Journal for Research in Mathematics Education, 37, 421-456.

Watanabe, T. (2006). The teaching and learning of fractions: A Japanese perspective. Teaching Children Mathematics, 12, 368 374.

Woodward, A. (1987). Textbooks: Less than meets the eye. Journal of Curriculum Studies, 19, 511-526. doi:10.1080/00220278701 90604. 